УДК [330.341.1+ 339.972]

\title{
ОЦЕНКА АДАПТИВНОСТИ СТРАН-ЧЛЕНОВ ЕАЭС К ИНВЕСТИЦИОННЫМ ПРОЦЕССАМ В УСЛОВИЯХ АКТИВИЗАЦИИ РЕГИОНАЛЬНОЙ ЭКОНОМИЧЕСКОЙ ИНТЕГРАЦИИ
}

\author{
А.Ш. МАРГАРЯН \\ канд. экон. наук, доцент, декан факультета регулирования экономики \\ и международных экономических отношений Армянского \\ государственного экономического университета, г. Ереван, Армения

\section{С.Ю. СОЛОДОВНИКОВ} \\ д-р экон. наук, профессор, \\ заведующий кафедрой «Экономика и право» \\ Белорусского национального технического университета, г. Минск

\section{Д.Р. ГАЛОЯН} \\ д-р экон. наук, доцент кафедры международных экономических \\ отношений Армянского государственного экономического университета \\ г. Ереван, Армения
}

Исследование выполнено при поддержке ГКН МОН РА в рамках совместного Армяно-Белорусского исследовательского проекта № 13 РБ059 (финансовая поддержка Государственного комитета науки при Министерстве образования и науки РА).

\section{Аннотация}

Решение основных экономических проблем в рамках регионального интеграиионного объединения тесно связано с необходимостью улучшения инвестиционных и экономических отночений и структуры экономик, входящих в него стран для повыщения конкурентоспособности, как самих этих стран, так и всего объединения в глобальной экономике.

Анализ мирового опыта и история становления и развития новых независимых государств в постсоциалистический период показывают, что противостоять вызовам и угрозам XXI века можно лишь на базе многопланового $и$ разностороннего межгосударственного инвестиичионного сотрудничества.

В данной статье, с помощью эмпирического межстраслевого анализа, оценена связь между макроэкономическими показателями и потоками иностранных инвестиций стран членов Евразийского экономического 
союза с цеелью выявления чувствительных к инвестициям областей национальных экономик.

Ключевые слова: инвестиции, адаптивность, интеграция, макроэкономические показатели, диссперсионная модель.

\section{Abstract}

Atom Margaryan, Sergej Solodovnikov, Diana Galoyan- Evaluation of adaptiveness of EAEU Member states to investment processes in the Conditions of Regional economic Integration Activization.

The solution of basic economic problems in the framework of regional integration unions is closely linked to the need of improving the investment and economic relations, as well as the economic structure of member countries, which aims to enhance both the competitiveness of individual economies and the competitiveness of the union in global economy.

Analysis of international experience and the history of the development of new independent states in the post-socialist period show that the challenges and threats of the XXI century can be confronted only based on a multi-faceted and versatile interstate investment cooperation.

In this article based on empirical cross-sectoral analysis the author has evaluated the dependence of macro-economic indicators and the flow of foreign investments of member countries of the Eurasian economic Union. It allowed identifying the sensitive to investments areas of national economies.

Key words: investments, adaptability, integration, macroeconomic indicators, dispersion model.

\section{ВВЕДЕНИЕ}

Сегодня, в условиях международной конкурентной борьбы, на первый план выходят международные компании с открытым доступом к международным потокам прямых инвестиций, что в дальнейшем принимает во внимание способность традиционной теории объяснить и предсказать растущую важность использования инструментов привлечения прямых иностранных инвестиций (ПИИ). Улучшение инвестиционного потенциала национальных экономик дает возможность повышения конкурентоспособности и возможного увеличения роста ВВП, что в совокупности скажется на росте инвестиционного потока в регион. Созданная в 2012 г. Евразийская экономическая комиссия, как наднациональный орган Евразийского экономического Союза (ЕАЭС) позволяет курировать вопросы инвестиционной деятельности, вести мониторинг и анализ инвестиционных поступлений. 
Однако распределение поступающих инвестиций будет неравномерным, поскольку у всех государств различные сравнительные конкурентные преимущества и инвесторы имеют право выбора наиболее привлекательной части региона ЕАЭС, что в целом может привести к реорганизации и дифференциации целого ряда производственной деятельности, а, следовательно, и перетоку капитала в рамках государств ЕАЭС. Для понимания перспективности избирательного поведения инвестора следует рассмотреть экономические позиции стран ЕАЭС.

\section{РЕЗУЛЬТАТЫ И ИХ ОБСУЖДЕНИЕ}

Наиболее выгодными приоритетами для создания бизнеса из стран ЕАЭС являются экономики Казахстана и России - наблюдается положительная динамика показателей прироста инвестиций в 2014 г. Республика Беларусь и Республика Армения имеют обратную динамику. Именно поэтому инвестиционный эффект будет здесь не ярко выражен. Рассмотрим динамику инвестиционного сотрудничества для развития ЕАЭС (рисунок 1). Анализ объёмов прямых инвестиций 2009-2014гг. в ЕАЭС показывает, что сотрудничествостран-членов не оказало существенного влияния на потоки иностранных инвестиционный. С точки зрения притока ПИИ очевидно улучшение показателя Беларуси, особенно в 2011 году, когда объем инвестиций достиг 4 млрд. долларов США. Однако после членства в ЕАЭС, инвестиции сократились в два раза.

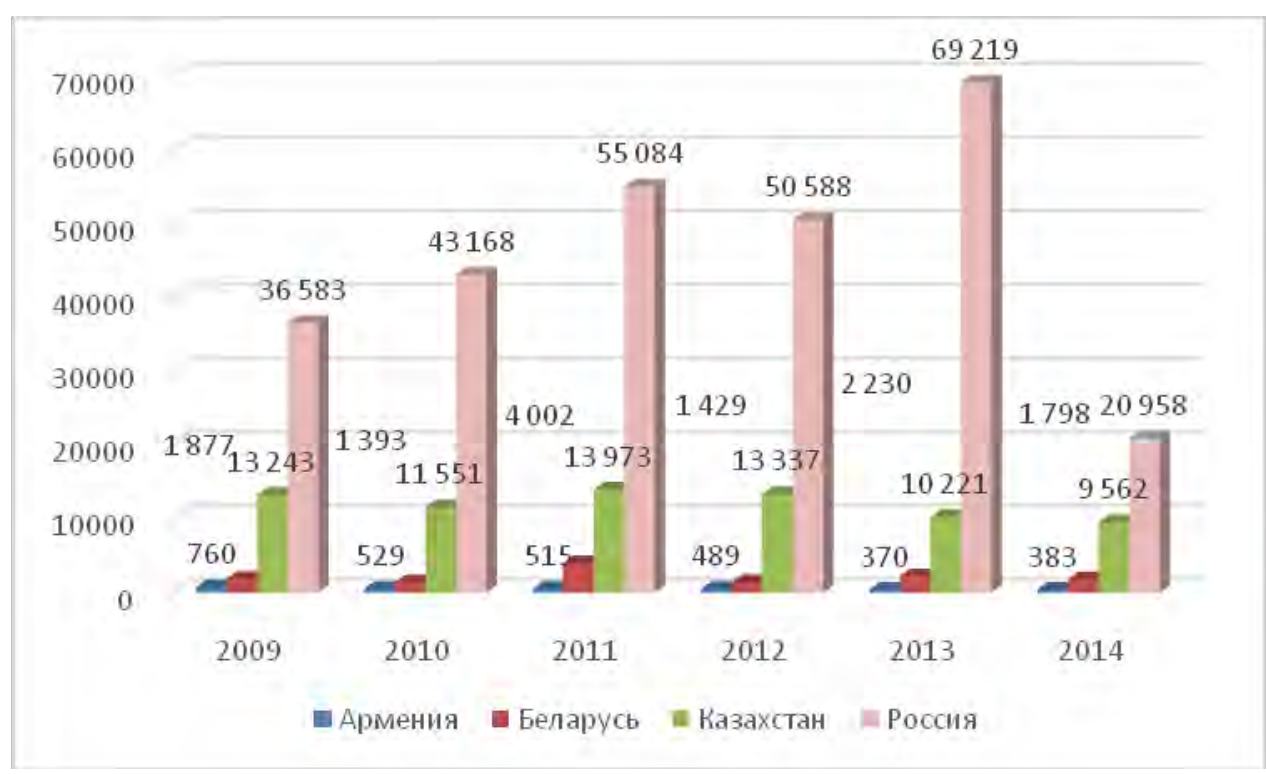

Рисунок 1 - Динамика притока инвестиций в страны ЕАЭС (млн долларов). Источник: World Investment Report 2015: Reforming International Investment Governance 
В 2014 году в Казахстане объем инвестиций сократился более чем на 29\% по сравнению с годом присоединения к Евразийскому экономическому союзу. Что касается Армении, поскольку Армения вступила в ЕАЭС 1 января 2015 г., то цифры, представленные в рисунке, не могут считаться результатом интеграции страны с членами ЕАЭС. Тем не менее, с начала 2013 года страна проводить политику, направленную на членство в ЕАЭС, что по существу привело к потере заинтересованности западных стран в экономике страны. Российские инвестиции существенно росли до 2013 года. В 2014 году, по сравнению с 2013г., инвестиции сократились на 48,3 млрд. долларов, что, конечно же, обусловлено политикой экономической изоляции США и европейских стран по отношению к России, а также продолжающимся глобальным финансовым кризисом. В том же году, инвестиции, сделанные Российской Федерацией, также были сокращены в размере 30,0 млрд. долларов, в то время как в 2013 году они достигли максимума последних шести лет.

Анализ инвестиционного потенциала стран-членов Евразийского экономического союза, а также проведенное эмпирическое исследование дали возможность оценить инвестиционные возможности Армении и стран ЕАЭС, и разработать рекомендации по их расширению. Для определения ключевых экономических областей, влияющих на инвестиции, проанализирована связь между основными макроэкономическими показателями и ПИИ обсуждаемых стран. Для сравнительного анализа были исследованы показатели, влияющие на развитии регионального сотрудничества: приток ПИИ, стабильность валютного курса, объем промышленного производства, стабильность инфляции, валютные шоки, реальные шоки, монетаризация ВВП. Исследование проводилось на основе макроэкономических показателей 2006-2014 гг. Было проведено междисциплинарное эмпирическое исследование, в ходе которого 7 индикаторов с 36 наблюдениями были рассчитаны и исползованы.

Таким образом, для исследования были проведены следующие действия:

1. Анализ основных макроэкономических показателей исследуемых стран. На первом этапе исследования макроэкономические показатели всех стран были сопоставлены с соответствующими показателями России, так как с точки зрения экономического и инвестиционного сотрудничества, Россия является самой мощной страной в регионе и основным торговым и инвестиционным партнером РА (таблица 1). 
Таблица 1 - Сравнительный анализ макроэкономических показателей стран ЕАЭС с РФ

\begin{tabular}{|c|c|c|c|c|c|c|c|}
\hline Страны & $\begin{array}{c}\text { Вес } \\
\text { ПИИ }\end{array}$ & $\begin{array}{c}\text { Стабильность } \\
\text { обменного } \\
\text { курса }\end{array}$ & $\begin{array}{c}\text { Объем } \\
\text { промышленного } \\
\text { произвдства }\end{array}$ & $\begin{array}{c}\text { Стабильность } \\
\text { инфляции }\end{array}$ & $\begin{array}{c}\text { Валютные } \\
\text { шоки }\end{array}$ & $\begin{array}{c}\text { Реальные } \\
\text { шоки }\end{array}$ & $\begin{array}{c}\text { Монетаризация } \\
\text { ВВП }\end{array}$ \\
\hline Армения & 0,6711 & 0,0807 & 0,0323 & 0,0088 & 0,0081 & 0,0279 & 0,3573 \\
\hline Беларусь & 0,5672 & 0,2132 & 0,045 & 0,1371 & 0,0009 & 0,0791 & 0,3699 \\
\hline Казахстан & 0,7577 & 0,0303 & 0,0069 & 0,0108 & 0,0409 & 0,0443 & 0,4312 \\
\hline Киргизия & 0,9231 & 0,0611 & 0,0038 & 0,0603 & 0,0228 & 0,0624 & 0,3829 \\
\hline В среднем & 0,7330 & 0,0977 & 0,0513 & 0,0439 & 0,0267 & 0,0467 & 0,4111 \\
\hline
\end{tabular}

2. Эмпирическое исследование, которое фокусируется на оценке зависимости притока прямых иностранных инвестиций и других макроэкономических показателей наблюдаемых стран.

Эмпирическая модель исследовании следующая:

FD (FDIij) $=\alpha_{0}+\alpha_{1} \mathrm{SD}($ Eij $)+\alpha_{2} \mathrm{SD}($ IPij $)+\alpha_{3} \mathrm{SD}(\mathrm{CPIij})+\alpha_{4} \mathrm{SD}(\mathrm{Mij})+$ $+\alpha_{5} \mathrm{SD}(\mathrm{Yij})+\alpha_{6} \mathrm{FD}(\mathrm{GDPij})+\xi \mathrm{ij}$;

FD $($ FDIij $)=0.586+3.5$ SD (IPij) +1.28 SD (CPIij) + 1.9 SD (Mij) - $3.3 \mathrm{SD}($ Yij) - 0.47 FD (GDPij) + $\xi \mathrm{ij}$.

Результаты анализа данных и расчета соответствующих показателей представлены в таблице 2.

Вес ПИИ. Высокое значение этого показателя свидетельствует о том, что страна обеспечивает хорошую среду для притока прямых иностранных инвестиций. Среднее значение, которое составляет 0,733, считается рассчетным.

Таблица 2 - Резюме расчетных показателей

\begin{tabular}{|c|c|c|c|c|c|c|c|c|c|}
\hline Страны & $\underset{\Theta}{\Xi}$ & 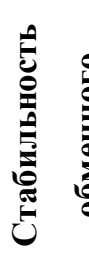 & हू & $\begin{array}{l}\bar{E} \\
\overline{0} \\
0 \\
0\end{array}$ & 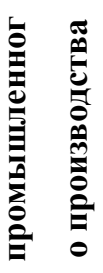 & 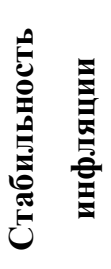 & 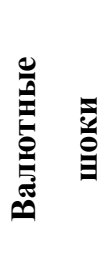 & 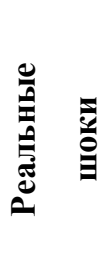 & 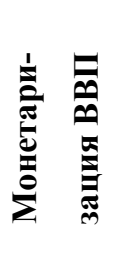 \\
\hline Армения & & & & & & $\mathrm{V}$ & $\mathrm{V}$ & & \\
\hline Беларусь & & & & & & & V & & \\
\hline Казахстан & $\mathrm{V}$ & $\mathrm{V}$ & & & $\mathrm{V}$ & $\mathrm{V}$ & & & $\mathrm{V}$ \\
\hline Киргизия & $\mathrm{V}$ & & & & $\mathrm{V}$ & & & & \\
\hline
\end{tabular}

Стабильность обменного курса. Высокое значение этого показателя означает, что страна может иметь высокие расходы. Одна треть среднего значения, которое является показателем колебания к российскому рублю 
и составляет 0,049, считается рассчетным. По этому показателю самое большое колебание у Беларуси, а показатель Казахстана соответствует условию.

Объем промышленного производства. Высокое значение этого показателя представляет собой огромную асимметрию реальных шоков. Полученные результаты показывают, что половина среднего показателя составляет 0,025. На основе полученных результатов, только Казахстан и Кыргизия имеют низкие значения колебаний.

Стабильность инфляции. Различия и колебания уровня инфляции приводят к колебаниям валютных курсов. Для описания колебаний в исследуемых странах, половина среднего показателя $(0,022)$ считалось минимальным значением. В эту группу вошли Армения и Казахстан.

Валютные шоки. Различия денежно-кредитных политик в исследуемых странах, характеризуются различными уровнями инфляции, что приводит к различиям покупательной способности. Половина среднего показателя $(0,013)$ посчиталось минимальным значением. В эту группу вошли Армения и Беларусь.

Реальные шоки. Высокие значения коэффициента корреляции между двумя странами отражают тот факт, что в этих экономиках происходят симметричные шоки. В данном случае порогом считалась половина среднего показателя - 0,023, которому не соответствует ни одна из исследуемых стран.

Монетаризация ВВП. Среднее значение этого показателя составляет 0,411 и, соответственно, самый высокий показатель у Казахстана.

Данные свидетельствуют о том, что из наблюдаемых стран только показатели Казахстана отвечают большинству критериям.

Во второй части исследования, мы провели эмпирический межотраслевой анализ и попарно сравнили показатели всех стран (таблица 3).

Таблица 3 - Результаты эмпирического межотраслевого анализа

\begin{tabular}{|c|c|c|c|c|c|}
\hline \multicolumn{6}{|c|}{ Зависимая переменная - ПИИ } \\
\hline \multirow{2}{*}{$\begin{array}{l}\text { Объем } \\
\text { промышленного } \\
\text { производства }\end{array}$} & $3,51 * *$ & \multirow{2}{*}{$\begin{array}{l}\text { Валютные } \\
\text { шоки }\end{array}$} & 1,93 & \multirow{2}{*}{$\begin{array}{l}\text { Монетаризация } \\
\text { ВВП }\end{array}$} & $-0,471$ \\
\hline & 1,66 & & 2,89 & & 0,64 \\
\hline \multirow{2}{*}{$\begin{array}{l}\text { Стабильность } \\
\text { инфляции }\end{array}$} & 1,28 & \multirow{2}{*}{$\begin{array}{l}\text { Реальные } \\
\text { шоки }\end{array}$} & $-3,31 * *$ & \multirow{2}{*}{ Константа } & 0,586 \\
\hline & 1,47 & & 1,478 & & 0,362 \\
\hline \multicolumn{2}{|c|}{ Наблюдения - 36} & & \multicolumn{3}{|c|}{$* * * \mathrm{p}<0,01 * * \mathrm{p}<0,05, * \mathrm{p}<0,1$} \\
\hline
\end{tabular}

Наблюдались 7 показателей, из которых 1 является независимой переменной (вес ПИИ), в то время как остальные 6 являются зависимыми переменными, которые оказывают существенное или не существенное, положительное или отрицательное влияние на независимую переменную. 
Результаты показывают, что с точки зрения объема промышленного производства, стабильности инфляции и валютных шоков связь с ПИИ положительная, что соответствует нашей теоретической гипотезе. Другие переменные, такие как реальные шоки и монетаризация ВВП негативно влияют на объем притока ПИИ, так как рост этих показателей на один пункт приводит к снижению объемов ПИИ соответственно на $-3,31$ и $-0,47$ пунктов. Почти все показатели статистически достаточно высоки, за исключением монетаризации ВВП, которая не очень хорошо описывает представленную модель, но в то же время влияние этого показателя не отвергает теоретическую гипотезу. Проверены также параметры, которые показывают свойства ошибок модели: дисперсия ошибок модели постоянна, так как между ними нет автокорреляции.

\section{ВЫВОДЫ}

1. Эмпирические данные показывают, что объем промышленного производства оказывает существенное положительное влияние на привлечения ПИИ: увеличение объема промышленного производства на 1 пункт приводит к увеличению объема ПИИ на 3,5 пункта.

2. Структурные, правовые и интеграционные различия между наблюдаемыми странами влияют на их способность противостоять экономическим потрясениям и на проведение экономической политики. Таким образом, в рамках Союза важное значение имеет существование таких режимов и инфраструктур, которые унифицируют воздействия различных потрясений на экономики стран.

В данный момент на постсоветском пространстве, углубление региональной интеграции имеет постоянный характер и поэтому обеспечение устойчивого социально-экономического развития странчленов должно стать приоритетом регионального экономического сотрудничества. Оно должно быть основано на инновационной модели и глубоком сотрудничестве в экономической и денежно-кредитной сфере.

Таким образом, для привлечения инвестиций должны быть предприняты следующие шаги:

-разработка четких шагов и мер устранения административных барьеров для привлечения инвестиций и реализации инвестиционных проектов;

-пересмотр инвестиционного законодательства, укрепление системы защиты инвестиций и государственных гарантий;

-внедрение методов оценки влияния государственного регулирования, а также административных барьеров на бизнес-среду; 
-обеспечение обратной связи с представителями бизнес-сообщества для осуществления эффективного диалога между государством и частным сектором;

-сокращение перечня типов лицензионных видов деятельности, за исключением случаев, когда это относится к правам человека и государственной безопасности.

\section{ЛИТЕРАТУРА}

1. Багратян Г. Мегаэкономика и глобальные экономические проблемы // Учебно-методическое пособие, РАУ, Ереван 2013, - 249 с.

2. Брандт Б. Иностранные капиталы, их влияние на экономическое развитие страны, Print-on-Demand 2012 - 469 с.

3. Гельвановский М.И. Методологические подходы к обеспечению конкурентоспособности международных интеграционных группировок в условиях глобализации, Евразийская экономическая интеграция, №1(14), февраль 2012, - с. 44-58.

4. Мониторинг Взаимных Инвестиций В Странах СНГ 2013, Евразийский банк развития, Доклад № 15, 2013 - 51 с.

5. Овчинников В., Глобальная конкуренция в эпоху многоукладной экономики // Институт экономических стратегий, Международная Академия исследований будущего, М. 2011 - 160 с.

6. Krugman P., International Economics: Theory and Policy (10th Edition) Prentice Hall, 2014 - 792 p.

Статья поступила в редакцию 03 сентябряя 2016 года. 